\title{
Asparaginase Like 1 Predicts Unfavourable Prognosis and Facilitates Gastric Cancer Progression Through Inhibits GSK3- $\beta$
}

Hao Yang

Central South University First Hospital: Xiangya Hospital Central South University https://orcid.org/0000-0003-0548-3040

Yiming Li

Xiangya Hospital Central South University

Yu Zhang

Xiangya Hospital Central South University

\section{Zhijun Zeng}

Xiangya Hospital Central South University

\section{Zhenhao Fang}

Xiangya Hospital Central South University

Junda Yin

Xiangya Hospital Central South University

Xi Li

Xiangya Hospital Central South University

Zhiyou Yang

Xiangya Hospital Central South University

\section{Ying Xiong}

Xiangya Hospital Central South University

Guodong Liu

Xiangya Hospital Central South University

Wei Wu ( $\nabla$ wwtw1972@126.com )

Central South University First Hospital: Xiangya Hospital Central South University

\section{Research}

Keywords: ASRGL1, GSK3- $\beta$, metastasis, prognosis, gastric cancer

Posted Date: August 31st, 2021

DOI: https://doi.org/10.21203/rs.3.rs-818123/v1 
License: (c) (i) This work is licensed under a Creative Commons Attribution 4.0 International License. Read Full License 


\section{Abstract}

\section{Background:}

ASRGL1 plays critical roles in various biological processes and pathologic conditions,

including cancer. However, the prognostic importance and biologic functions of ASRGL1 in gastric cancer (GC) are still unclear.

\section{Methods:}

qRT-PCR, western blot and immunohistochemistry analyses were used to determine ASRGL1 expression in GC samples and cell lines. The clinical significance of ASRGL1 was assessed in 100 patients with GC. A series of functional experiments were performed to explore the role and molecular mechanism of ASRGL1 on GC progression.

\section{Results:}

ASRGL1 was upregulated in GC tissues and cell lines. High ASRGL1 expression was closely correlated with aggressive clinicopathological features, poor clinical outcomes and recurrence of GC patients. Moreover, silencing ASRGL1 in AGS cells significantly inhibited cell proliferation, migration, invasion, whereas overexpression of ASRGL1 significantly enhanced the above abilities of BGC-823 cells. Further mechanism study indicated that these phenotypic changes were mediated by PI3K/AKT and WNT signaling. Finally, we proved that ASRGL1 exerted its tumor-promoting effect by interacting with GSK3- $\beta$.

\section{Conclusions:}

ASRGL1 is up regulated in gastric cancer, while it promotes the GC cell proliferation, migration and invasion via interacting with GSK3- $\beta$. At the same time it also serves as a potential prognostic factor in patients with GC. ASRGL1 can be used as a new target for diagnosis and treatment of gastric cancer.

\section{Background}

Gastric cancer (GC)is a globally important disease. Almost half of the worldwide GC incidence occurs in China $^{1,2}$. With over 1 million estimated new cases annually, gastric cancer is the fifth most diagnosed malignancy worldwide ${ }^{3}$. Due to its frequently advanced stage at diagnosis, mortality from gastric cancer is high, making it the third most common cause of cancer-related deaths, with 784000 deaths globally in $2018^{1}$. Gastric cancer is a molecularly and phenotypically highly heterogeneous disease. In recent years, with the continuous progress of medical imaging diagnosis, surgery technology and drugs for gastric cancer, early diagnosis and treatment for gastric cancer has been more effectively. The main treatment for early gastric cancer is endoscopic resection. Non-early operable gastric cancer is treated with surgery, which should include D2 lymphadenectomy. Perioperative or adjuvant chemotherapy improves survival in patients with stage 1B or higher cancers ${ }^{3}$. However, the median survival time of IV-stage gastric cancer is 
still between 8 and 10 months $^{2}$, and the overall treatment level of advanced gastric cancer is generally low. The main reason is that gastric cancer cells are highly invasive, leading to high recurrence and metastasis rates after radical surgery, which greatly restricts the overall survival of patients. It has been generally accepted that the invasive and metastatic potentials of GC are mostly attributed to the differences of pathological and molecular characteristics ${ }^{4,5}$. Therefore, study the mechanism of the occurrence and development of gastric cancer is an urgent issue. Finding suitable predictors, target molecules and prognostic molecular markers for gastric cancer may be a good way to solve the above problems. Consequently, we first analyzed the differentially expressed genes between paired gastric cancer tissues and adjacent gastric tissues in TCGA database. Through the analysis of TCGA database, we found that the expression difference of ASRGL1 (asparaginase like 1, ID: 80150) between paired gastric cancer and adjacent gastric tissue samples in TCGA database was 2.136 (the ratio of expression between cancer samples and adjacent gastric tissue samples with statistical significance $P<0.05$ ). It is suggested that ASRGL1 may be associated with the occurrence and development of gastric cancer.

Recent studies have shown that ASRGL1 as a asparaginase-like factor is widely involved in the process of tumorigenesis and development. ASRGL1, also known as CRASH, consists of 307 amino acids. The molecular weight is $31.9 \mathrm{kD}$. It is predicted to have L-asparaginase-like structure and activity ${ }^{6,7}$. In nontransformed tissues, ASRGL1 was detected only in testis, brain, esophagus, prostate and proliferating endometrium. On the other hand, ASRGL1 was detected in some ovarian carcinomas, breast carcinomas, urothelial carcinomas and colon carcinomas, but not in the corresponding normal tissues ${ }^{6,7}$. ASRGL1 are involved in many key control pathways, such as cell proliferation, apoptosis and metastasis ${ }^{6-8}$. Some studies have reported that the high expression of ASRGL1 is closely related to the occurrence and development of tumors ${ }^{6,7}$. For example, 11 out of 16 breast cancers expressing ASRGL1 are metastatic, suggesting that ASRGL1 is associated with tumor progression and invasion. 28 out of 42 endometrium tumors expressed CRASH at high levels as did 5/41 prostate carcinomas, as well as ovary and breast cancers, indicating a regulation of CRASH expression by sex hormones ${ }^{6,7}$.

Asparaginase-like proteins play a role in the growth regulation and signal transduction of P70 S6 kinase. Knockout of ASRGL1 significantly inhibited the growth of KM12L4A colon cancer cells (which expressed ASRGL1 in large quantities), while the proliferation of the syngeneic, weakly expressed and slowly growing KL12SM colon cancer cells was not affected ${ }^{6,7}$. In endometrial carcinoma, loss of the gene encoding ASRGL1 has previously been reported as part of a 29-gene signature associated with features of aggressive disease and poor recurrence-free survival ${ }^{9,10}$. Loss of ASRGL1 in primary endometrial carcinoma has also been suggested to be an independent biomarker for disease-specific survival in a subgroup of patients with endometrioid endometrial carcinoma ${ }^{11}$. These results suggest that the high expression of ASRGL1 is closely related to the occurrence and development of tumors. Therefore, ASRGL1 may be used as a new target for diagnosis and treatment of tumors.

However, there are no reports of ASRGL1 related to gastric cancer up to now. This study is to investigate the expression of ASRGL1 protein and its role in gastric cancer cells through molecular biology studies, 
and to provide theoretical basis for new-targeted drugs and therapies.

\section{Methods}

Patients and Tissue Specimens. A total of 40 pairs of randomly selected snap-frozen and adjacent nontumor gastric tissues (ANGTs) from consecutive patients who have received gastrectomy for GC at the Department of Geriatric Surgery, Xiangya Hospital of Central South University (CSU) from January 2018 to October 2018. Besides, a total of 100 pairs of paraffin-embedded GCs and adjacent nontumor gastric tissues (ANGTs) from consecutive patients who have received gastrectomy for GC at the Department of Geriatric Surgery, Xiangya Hospital of Central South University (CSU) from January 2006 to December 2018. We also obtained the normal gastric tissue from a gastric ulcer patient who has received gastrectomy. Diagnosis of GC was confirmed by two independent histopathologists. In total 63 males and 37 females with a median age of 49.5 years (range: $25-78$ ) were included for the study. The related clinicopathological characteristics of these samples are presented in the Table 1. Prior informed consent was obtained and the study protocol was approved by the Ethics Committee of Xiangya Hospital of CSU.

Cell Lines and Cell Culture. GES-1, AGS, SGC-7901, MGC-803, BGC-823 cells were obtained from the Tumor Institute of Central South University, Changsha, China. These cells were cultured in High glucose Dulbecco's modified Eagle media (GIBCO BRL, Gaithersburg, MD) supplemented with $10 \%$ fetal bovine serum (HyClone, Logan, UT) and $5 \% \mathrm{CO} 2$ at $37^{\circ} \mathrm{C}$.

Quantitative Real-time Quantitative PCR (qRT-PCR). qRT-PCR was performed using TaqMan® Universal PCR Master Mix (Ambion, TX) and TaqMan ${ }^{\circledR}$ MicroRNA reverse transcription kit as instructed. Real time RT-PCR was performed using a PRISM 7300 Sequence Detection System (Applied Biosystems, CA), in which each reaction ( $25 \mathrm{ul}$ ) contained 10ul PCR Master Mix (Ambion, TX,) and 1.33ul RT product, and each sample was analyzed in triplicates. PCR was carried out at $95^{\circ} \mathrm{Cfor} 10 \mathrm{~min}$, followed by 40 cycles of amplification at $95^{\circ} \mathrm{C}$ for $15 \mathrm{~s}$ and $60^{\circ} \mathrm{C}$ for $60 \mathrm{~s}$. Results are representative of two independent assays. Relative fold changes of expression in tumor tissues against nontumor samples and among different cell lines were calculated using the comparative $\mathrm{Ct}\left(2^{-} \Delta \Delta \mathrm{Ct}\right)$ method with $\mathrm{U} 6$ small nuclear RNA (Ambion, TX) as the endogenous control.

Western Blotting analysis. Total proteins were extracted and separated by sodium dodecyl sulfatepolyacrylamide gel electrophoresis (SDS-PAGE) and then transferred onto PVDF membrane (Millipore, Bedford, MA). The blotted membranes were incubated with antihuman ASRGL1 antibody (1:1000, Santa Cruz Biotechnology, Santa Cruz, CA), and then probed with a secondary antibody (1:3000, Santa Cruz Biotechnology) Beta-actin was used as a loading control.

Immunohistochemistry. Formalin-fixed paraffin sections were stained for ASRGL1 using the streptavidinperoxidase system (Zhong-shan Goldenbridge Biotechnology, Beijing, China). Negative control slides were 
probed with goat serum followed by the secondary antibody under the same conditions. The IHC score of target proteins was

independently evaluated by two investigators according to the proportion and intensity of positive cells within five randomly selected fields per slide (magnification, $\times 400$ ). The intensity was assessed by four grades: 0 for none, 1 for weak, 2 for moderate, 3 for strong. The percentage of positive cells was divided into five degrees: 0 ,no positive tumor cells, 1 for $\leq 5 \%, 2$ for $6-25 \%, 3$ for $26-75 \%, 4$ for $\geq 76 \%$. Immunoreactive score was calculated by multiplying the staining extent score with the intensity score. High expression was defined as a staining index score $>4$, while low expression was defined as a staining index score $\leq 4^{12}$.

Follow-up and Prognostic Study. Follow-up data were obtained after gastrectomy for all 100 patients. All research protocols strictly complied with REMARK guidelines for reporting prognostic biomarkers in cancer ${ }^{13}$. The average observation time for overall survival and disease-free survival were 53.3 months (4.0 to 150 months) and 50 months ( 0.7 to 150 months), respectively. Among all patients analyzed, 42 of which were died during the follow-up period, while 53 patients were found with tumor recurrence. The follow-up period was defined as the interval between the date of operation and the deadline (December 2018). Recurrence and metastasis were diagnosed by clinical examination, gastroscope, ultrasonography and computed tomography (CT) scan. To determine factors influencing survival after gastrectomy, 7 conventional variables were tested in all 100 patients, which include gender, age, histological grade, T stage, lymph node metastasis, TNM stage and ASRGL1 expression levels.

Vector Construction and Cell Transfection. The DNA fragment for ASRGL1 was amplified from genomic DNA and inserted into the Age I/EcoR I site of a lentiviral expression vector pGCSIL-GFP (GeneChem, Shanghai, China). The ASRGL1 expression vector were constructed by inserting their ORF sequence into the pGCL vector (GeneChem, Shanghai, China). Cell transfection was performed according to the protocol of manufactures. Viruses were harvested 72 hours after transfection and viral titers were determined $\left(1 \times 10^{9} \mathrm{TU} / \mathrm{ml}\right) .1 \times 10^{5}$ cells were infected with $2 \times 10^{6}$ lentivirus in the presence of $6 \mathrm{ug} / \mathrm{ml}$ polybrene (Sigma, MO). In the present study, the infection efficiency of lentivirus was over $90 \%$. There were no significant cell death been observed after virus infection, and bulk transfectants were used for subsequent assays.

Cell Proliferation and Colony Formation Assays. Cell proliferation was determined by counting the number of cells using TC10TM automated cell counter (Bio Rad, CA). For colony formation assays, 500 cells were seeded into $35 \mathrm{~mm}$ dishes (Corning, NY) and cultured for 2 weeks at $37^{\circ} \mathrm{C}$. The numbers of colonies per dish were counted after staining with crystal violet. All studies were conducted with 3 replicates.

In Vitro Wound Healing (Migration) and Invasion Assays. Cells were seeded onto $35 \mathrm{~mm}$ dishes coated with fibronectin. After the cells reached $100 \%$ confluence, wound healing assays were performed with a sterile pipette tip to make a scratch through the confluent monolayer. Mitomycin $\mathrm{C}(10 \mu \mathrm{g} / \mathrm{mL})$ was used 
to suppress cell proliferation before scratching ${ }^{14}$. Medium was changed and the cells were cultured for another 48 hours. The percent of wound closure was calculated for five randomly chosen fields. For the invasion assay, $1 \times 10^{5}$ cells in serum-free medium containing $0.1 \%$ bovine serum albumin were placed into the upper chamber of the insert with Matrigel (BD Biosciences, MA). After 24 hours of incubation at $37^{\circ} \mathrm{C}$, the cells remained in the upper chamber or on the upper membrane were removed. The number of cells adhering to the lower membrane of the inserts was counted after staining with a solution containing $0.1 \%$ crystal violet and $20 \%$ methanol.

\section{Annexin V-APC single staining flow cytometry}

The gastric cancer cells in different groups were induced apoptosis (when the coverage rate of cells in the two groups was $70 \%$ ). Cells in each group were digested by trypsin, and the cell suspension was resuspended in the complete medium. The cells were collected in the same $5 \mathrm{ml}$ centrifuge tube with the supernatant cells. After centrifugation, the supernatant was removed and the cell precipitates were washed with d-hanks at $4{ }^{\circ} \mathrm{C}$. The cells were washed with $1 \times$ binding buffer once, then centrifuged and collected. $1 \times$ binding buffer was used to resuspend cell precipitation. Annexin V-APC was added for dyeing, then stand at room temperature for $10 \mathrm{~min}$ (light was avoided). According to the number of cells, add 400-800 $\mu \mathrm{L} 1 \times$ binding buffer, and finally test on the flow cytometry (Millipore, USA). (This step uses the ebioscience apoptosis Kit).

\section{Caspase $3 / 7$ detection}

Gastric cancer cells were cultured for 3 days. At room temperature, add $10 \mathrm{ml}$ of caspase-glo3/7 buffer solution into the brown bottle containing caspase-glo3/7 substrate (pay attention to avoid light), shake repeatedly until the substrate dissolves, and obtain Caspase-Glo reaction solution. The gastric cancer cells were counted and the cell suspension concentration $\left(1 \times 10^{4}\right.$ cells / well) was adjusted. Then the cells

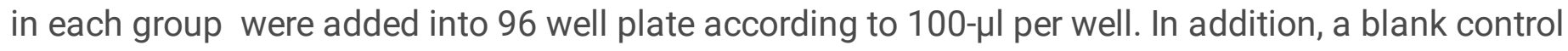
group without cells was designed (only culture medium was added). $100 \mu \mathrm{l}$ Caspase-Glo reaction solution was added into each well. The culture plate with cells was placed on the shaking machine and gently shaken for about 30 minutes (rotating speed 300-500 RPM) so that the cells and the reaction solution were fully mixed. The cells were then incubated at room temperature (about $22^{\circ} \mathrm{C}$ ) for one hour. Finally, the signal strength is measured by the enzyme labeling instrument (Tecan infinite, Switzerland). (This step uses Promega caspase glo ${ }^{\circledR} 3 / 7$ assay Kit).

\section{Cancer 45-pathway reporter arrays}

A Cignal 45-Pathway Reporter Array (Qiagen, Valencia, CA) was performed to explore the signaling pathways that were regulated by ASRGL1 in GC cells. The assay was conducted according to the manufacturer's protocol. Relative firefly luciferase activity was calculated and normalized to the constitutively expressed Renilla luciferase. Experiments were done in triplicates. 
Statistical analysis. Statistical analysis was performed using the SPSS (version 13.0, Chicago, IL). Data for ASRGL1 expression in snap-frozen and paraffin-embedded specimens were analyzed using the Mann-Whitney U-test. Fisher's exact test was used for statistical analysis of categorical data. Spearman correlation test was used for analyzing the correlations between ASRGL1 expression level and the clinical and pathological variables. Survival curves were constructed using the Kaplan-Meier method and evaluated using the log-rank test. The cox proportional hazard regression model was used to identify factors that were independently associated with overall survival (OS) and relapse-free survival (RFS). In any case, $\mathrm{P}<0.05$ was considered with statistical significance.

\section{Results}

\section{ASRGL1 is up-regulated in GC tissues and cell lines.}

Stomach adenocarcinoma (STAD ) In TCGA database, there are 443 samples with available data, including 416 samples with mRNA microarray or RNA-seq data. Among these database, there are 32 paired samples with RNA-seq V2 data and pathological information (Table S1). Our expression profile analysis is based on these paired sample RNA-seq data. The original data used for analysis needs to be filtered and standardized before entering the subsequent statistical analysis. For each gene symbol, we only select the transcript with the highest expression level for analysis. If the number of original reads of all samples corresponding to the symbol is less than 50 , then the data of the symbol will be regarded as unavailable. TMM (trimmed mean of m-values) method is used in data standardization. This method is different from those standardized methods which directly estimate absolute counts according to the number of reads and transcript length. It uses the concept of relative expression between different samples to avoid the inaccuracy caused by rough absolute statistical methods. The standardized data can be used for statistical analysis of paired samples. However, in order to avoid the error caused by improper sample grouping, we observed the biological coefficient of variation (BCV) for quality control. Most samples of adjacent gastric tissue and cancer are obviously separated, which can be further analyzed (Figure 1A). For the statistical analysis of multiple paired samples, we first estimate the dispersion, and then use the general linear model to estimate whether there are differences in genes among different groups. The genes with $p \leq 0.05$ are considered to be differentially expressed genes that conform to the zero hypothesis (the points marked in red in figure 1B). At the same time, the expression difference multiples of genes in different groups were calculated. The calculation method used here was log2 (cancer / normal), and the filtering criteria were $\geq 1$ or $\leq-1$. After removing the genes that have been reported to be related to the occurrence and development of gastric cancer, we chose ASRGL1 for further study. The expression difference of ASRGL1 between paired gastric cancer and adjacent gastric tissue samples in TCGA database was 2.136 (Table S2, Figure 1C). We further compared the expression of ASRGL1 in 408 gastric cancer samples and 36 normal gastric tissues in TCGA database. The expression level of ASRGL1 in gastric cancer was significantly higher than that in normal gastric tissue (Figure 1D). To further confirm the results of TCGA database, we collected 40 paired of snap frozen gastric cancer and adjacent nontumor gastric tissues which were performed by real-time polymerase chain reaction (real time PCR) and western blotting to detect the expression of ASRGL1 in fresh GC tissues. Consistently with 
the results in TCGA data, the mRNA and protein expression of ASRGL1 in GC tissues was markedly higher than ANGTs and normal gastric tissue (Fig. 1E\&F). In addition, we also detected the mRNA and protein expression of ASRGL1 in gastric cancer cell lines and normal gastric cells. Compared with GES-1 cells, which are immortalized human normal stomach cells, ASRGL1 messenger RNA (mRNA) and protein were also highly expressed in GC cells (Fig. 1G\&H).

\section{ASRGL1 promotes GC cell proliferation and clonogenicity.}

To understand the function of ASRGL1 in GC cells, we manipulated ASRGL1 expression in cells by ectopic expression and short hairpin RNA (shRNA) knockdown. Ectopic ASRGL1 was constituently expressed in BGC-823 cells named as BGC-823- ASRGL1 subsequently. Meanwhile, shRNA was designed to silence ASRGL1 expression in AGS cells named as AGS-shASRGL1 subsequently. Expression level of ASRGL1 was identified by real-time PCR. Our results showed that the mRNA expression of ASRGL1 was significantly inhibited in AGS-shASRGL1 cells when compared to AGS-ctrl cells (Fig. 2A). Meanwhile, compared to BGC-823 cells, the mRNA expression of ASRGL1 was significantly strengthened in BGC-823ASRGL1(Fig. 2B). Cell proliferation assay showed that compared to BGC-823-ctrl cells, BGC-823-ASRGL1 had a higher proliferation rate (Fig. 2C). Consistently, BGC-823-ASRGL1 cells also formed more colonies in colony formation assay (Fig. 2E). In contrast, AGS-shASRGL1 cells had decreased cell proliferation rate and clonogenicity capacity when compared to AGS-ctrl cells (Fig. 2D, F). These suggest that ASRGL1 promotes GC cell proliferation capacity.

\section{ASRGL1 promotes GC cell migration and invasion.}

To explore the role of ASRGL1 in GC cell migration and invasion, we first analyzed the protein expression of ASRGL1 in GC tissues by immunohistochemistry (IHC). We found that ASRGL1 protein was highly expressed in GC tissues (Fig. 3A). Moreover, comparing samples of metastasis patients to nonmetastasis patients' samples and ANGTs, metastasis samples have the highest intensities of ASRGL1 staining, whereas ANGTs have the lowest intensities (Fig.3A). These data indicated that ASRGL1 was up-regulated in GC tissues and it might be correlated with GC invasion and metastasis.

Then, the wound-healing and transwell assays were used to investigate the influence of ASRGL1 in GC cells migration and invasion. Results showed that BGC-823-ASRGL1 cells had a faster wound closure rate and more invasion cells than BGC-823-ctrl cells (Fig. 3B,D), whereas AGS-shASRGL1 cells had markedly reduced migratory and invasive capacity compared to AGS-ctrl cells (Fig. 3C,E). These suggest that ASRGL1 promotes GC cell migration, and invasion capacity.

\section{ASRGL1 inhibits GC cell apoptosis.}

We also explored the role of ASRGL1 in GC cell apoptosis. We used Annexin V-APC single staining flow cytometry and Caspase 3/7 detection to detect cell apoptosis in each group. The results showed that AGS-shASRGL1 cells had markedly increased apoptosis cells compared to AGS-ctrl cells (Fig.4 A,C), 
whereas BGC-823-ASRGL1 cells had less apoptosis cells than BGC-823-ctrl cells (Fig.4 B,D). These results suggest that ASRGL1 can inhibit GC cell apoptosis.

\section{High ASRGL1 expression is associated with poor GC clinicopathological features and shorter survival.}

We then estimated the association of ASRGL1 expression with clinicopathological features and survival of GC patients. Our results showed that a high expression level of ASRGL1 was significantly associated with T stage and TNM stage (Table 1). GC patients in the high ASRGL1 expression group had shorter OS $\left(\right.$ Log Rank $\left.X^{2}=6.069, p=0.014\right)$ and RFS rates (Log Rank $\left.X^{2}=5.315, p=0.021\right)$ than patients in the lowexpression group (Fig. 5A-F). Furthermore, univariate and multivariate analysis revealed that lymph node metastasis, TNM stage and high ASRGL1 expression were independent risk factors for both OS and RFS of GC patients after gastric resection (Table $2 \&$ Table 3 ). These results fully demonstrated that ASRGL1 was closely correlated with poor survival and could be used as a novel independent prognosis biomarker for GC patients after gastric resection.

\section{ASRGL1 activates PI3K-AKT and Wnt/ $\beta$-catenin signaling through interacts with GSK3- $\beta$.}

To systemically screen the potential signaling manipulated by ASRGL1, a cignal 45-Pathway reporter array was performed. ASRGL1 significantly enhanced the activity of PI3K-AKT and Wnt/ $\beta$-catenin signaling in BGC-823 cells, and ASRGL1 knockdown attenuated PI3K-AKT and Wnt/ $\beta$-catenin signaling activity in AGS cells (Fig. 6A\&B). PI3K-AKT and Wnt/ $\beta$-catenin signaling is crucial for development and progression of gastric cancer, their aberrant activation modulates proliferation, differentiation, migration in gastric cancers ${ }^{15-17}$. In order to find out the target molecules of ASRGL1, we used a bioinformatics database (BioGRID ${ }^{4.4}$ https://thebiogrid.org) to predict the interaction molecules of ASRGL1. It used a "Two-hybrid" method to predict the interaction molecule. Bait protein (ASRGL1) expressed as a DNA binding domain (DBD) fusion and prey expressed as a transcriptional activation domain (TAD) fusion and interaction measured by reporter gene activation. By this means, GSK3- $\beta$ was predicted to interact with ASRGL1 (supplementary material Fig S1). GSK-3 $\beta$ has been proved to be involved in multiple signal pathway including Wnt/ $\beta$-catenin, PI3K/PTEN/AKT ${ }^{18}$. Then, we transfected the GSK3- $\beta$ ectopic expression plasmid into AGS-shASRGL1 cells, and GSK3- $\beta$-shRNA into BGC-823-ASRGL1 cells. The ectopic expression and silence efficacy of GSK3- $\beta$ was varified by qRT-PCR and western blot, respectively (supplementary material Fig S2). We found that overexpression of GSK3- $\beta$ in BGC-823-ASRGL1 cells eliminated the activated effect of ASRGL1 on PI3K-AKT and Wnt/ $\beta$-catenin signaling, whereas knockdown of GSK3- $\beta$ in AGS-shASRGL1 cells restored the PI3K-AKT and Wnt/ $\beta$-catenin signaling activity (Fig 6A\&B). Subsequently, we detected the expression levels of GSK3- $\beta$ and its downstream proteins in ASRGL1-interfered GC cells. Of note, when knockdown the expression of ASRGL1 by shRNA in AGS cells can significantly suppressed the expression of GSK3- $\beta$, phosphorylation of cyclin D1 AKT and phosphorylation of $\beta$-catenin, but the expression of cyclin D1, E2F1, p-AKT and $\beta$-catenin was strengthened. When added the inhibitor of GSK3- $\beta$, CHIR-98014 (Selleck Chemicals, Houston, TX, USA) to gastric cancer cells, the similar results with shRNA was got (Fig $6 \mathrm{C}$ ). On the contrary, when ASRGL1 was overexpressed in BGC-823 cells, we got the opposite result (Fig 6C). 


\section{ASRGL1 promtes GC cell growth, migration and invasion through inhibits GSK3- $\beta$.}

Next, whether GSK3- $\beta$-dependency on ASRGL1-mediated activation of GC progression was also assessed by gain-and-loss function assays. Our results showed that overexpression of GSK3- $\beta$ in BGC-823-ASRGL1 cells eliminated the promoting effect of ASRGL1 on gastric cancer cell proliferation, migration and invasion, whereas knockdown of GSK3- $\beta$ in AGS-shASRGL1 cells restored their proliferation and metastatic capacity (Fig $6 \mathrm{D}-\mathrm{G}$ ). Together, these results implied that ASRGL1 promotes GC growth and metastasis by regulating PI3K-AKT and Wnt/ $\beta$-catenin signaling via GSK3- $\beta$ in GC cells.

\section{Discussion}

Metastasis and recurrence are responsible for the vast majority of cancer associated deaths, including GC. Finding the key molecules affecting tumor recurrence and metastasis has always been an important topic. Although many biomarkers of GC have been reported, including carcinoembryonic antigen (CEA), CA19-9, CA72-4, CA12-5, SLE, BCA-225, hCG and pepsinogen I/II are still the most commonly used biomarkers in clinical practice of GC. Except for conventional biomarkers (CEA, CA19-9, etc.), only HER2 is currently in clinical application. However, the positive rate of HER-2 in gastric cancer is often not high. HER2-positivity rates across centers were only $19.8 \%$ and $30.5 \%$ in metastatic gastric or gastroesophageal junction cancer, respectively ${ }^{19}$. As a result, the application of targeted therapy for HER2 is not wide. New reliable biomarkers are needed to better identify patients who are likely to benefit from adjuvant therapy and to enable more accurate individualized treatment of gastric cancer. Therefore, we urgently need to find reliable, highly specific biomarkers that can early detect and guide the choice of treatment.

Previous studies have shown that ASRGL1 is highly expressed in a variety of tumors, while it is hardly detected in normal tissues. ASRGL1 was highly expressed in ovarian, breast, bladder and colon cancers $^{20-23}$. Northern blot analysis of rat tissues detected the highest expression of ASRGL1 in testis, with lower expression in brain, liver, kidney, heart and skeletal muscle ${ }^{22}$.

A large number of studies have shown that ASRGL1 plays an important role in the occurrence and development of tumors, and it has the potential to serve as a molecular marker for predicting tumors and a target for cancer treatment. For example, it was found that ASRGL1 mRNA levels correlate with the metastatic propensity of human colon cancer cell lines ${ }^{24}$. High levels of ASRGL1 mRNA were found in endocrine-dependent uterine, mammary and ovarian tumors when compared to the corresponding normal tissues ${ }^{7}$. Consistent with a regulatory role of endocrine-dependent signaling pathways, ASRGL1 mRNA can be induced by sex hormones in BT474 breast cancer cells ${ }^{25}$. However, the molecular significance and the role in GC metastasis of ASRGL1 are still elusive.

In the current study, we used qRT-PCR and WB to show that ASRGL1 levels in gastric cancer tissues were significantly higher than those in non-tumor tissues, which is consistent with the results of TCGA database. Moreover, the ASRGL1 levels were associated with T stage and TNM stage. Kaplan-Meier 
survival analysis revealed that patients whose primary tumors displayed high expression of ASRGL1 had shorter OS and RFS in GC. In addition, Cox proportional hazards regression analysis showed that increased ASRGL1 in tumors was a strong and independent predictor of shorter OS and RFS.

Furthermore, our findings also suggest that ASRGL1 could potentially be used as a biomarker to clinically predict metastasis and survival prognosis for the patients with GC.

The results derived from in vitro cell proliferation, apoptosis, colony formation, migration, invasion assays also showed that ectopic ASRGL1 expression promote the potency for GC cell proliferation and metastasis, while blocked ASRGL1 expression showed the opposite effect. These data further indicated that ASRGL1 functions as a tumor booster in gastric cancer. More importantly, we found that ASRGL1 can regulate the activity of PI3K-Akt and Wnt/ $\beta$-catenin signaling pathways. And then, through the BioGRID ${ }^{4.4}$ database, GSK-3 $\beta$ was predicted to interact with ASRGL1. As we know, initially discovered as a regulator of glycogen synthesis, GSK-3 is also involved in several signaling pathways (including PI3KAkt and Wnt/ $\beta$-catenin pathway) controlling many different key functions ${ }^{26}$. Western blotting results also confirmed that ASRGL1 could regulate the expression of GSK-3 $\beta$ and its downstream proteins. Functional experiment showed that over-expressed GSK-3 3 eliminated the promoting effect of ASRGL1 on gastric cancer. Our results implied that ASRGL1 might be a GSK-3 $\beta$ inhibitor. GSK-3 $\beta$ is involved in biological processes of tumorigenesis, therefore, it is rational that GSK-3 $\beta$ inhibitors were employed to target malignant tumors. The effects of GSK-3 $\beta$ inhibitors in combination of radiation and chemotherapeutic drugs have been reported in various types of cancers, suggesting GSK3- $\beta$ inhibitor would play important roles in cancer treatments ${ }^{18}$. Therefore, as an inhibitor of GSK3- $\beta$, ASRGL1 may has potential as a target for gastric cancer.

\section{Conclusions}

ASRGL1 is up-regulated in GC and possesses the potency to promote GC growth and metastasis through activate PI3K/AKT and Wnt/ $\beta$-catenin signaling pathway via GSK3- $\beta$. Therefore, ASRGL1 could function as a tumor facilitator in GC. The identification the role of ASRGL1 in GC would help in better understanding of the molecular mechanisms underlying GC development, which would provide us a wider prospective on GC intervetion/prevention and treatment.

\section{Abbreviations}

ASRGL1, asparaginase like 1, ANGT, adjacent nontumorous gastric tissues, GC, gastric cancer, OS, overall survival, RFS, relapse-free survival, qRT-PCR, Real-time quantitative PCR, CEA,carcinoembryonic antigen.

\section{Declarations}

\section{Ethics approval and consent to participate}

The studies were approved by the Ethics Committee of Xiangya Hospital of 
Central South University. Written informed consent was obtained from all patients.

\section{Consent for publication}

Not applicable

\section{Availability of data and materials}

The datasets during and/or analyzed during the current study available from the corresponding author on reasonable request.

\section{Competing interests}

The authors declare that they have no competing interests.

\section{Funding}

National Nature Science Foundation of China (No. 81873581). National Nature Science Foundation of China (No. 81502539). Nature Science Foundation of Hunan (2019JJ40493). Nature Science Foundation of Xiangya (No. 2013Q07).

\section{Authors' contributions}

Haoyang conceived the study and wrote the manuscript, Hao Yang, Yiming Li and Yu Zhang conducted the experiments and contributed to the analysis of data. Zhijun Zeng, Zhenhao Fang, Junda Yin, Xi Li, Zhiyou Yang, Ying Xiong and Guodong Liu collected clinical samples and corresponding clinical data. Wei Wu revised the manuscript. All authors read and approved the final manuscript.

\section{Acknowledgements}

Not applicable

\section{References}

1. Bray F, Ferlay J, Soerjomataram I, et al. Global cancer statistics 2018: GLOBOCAN estimates of incidence and mortality worldwide for 36 cancers in 185 countries. CA Cancer J Clin 2018,68:394424.

2. Shah MA. Update on metastatic gastric and esophageal cancers. J Clin Oncol 2015,33:1760-9.

3. Smyth EC, Nilsson M, Grabsch HI, et al. Gastric cancer. Lancet 2020,396:635-648.

4. Wadhwa R, Song S, Lee JS, et al. Gastric cancer-molecular and clinical dimensions. Nat Rev Clin Oncol 2013,10:643-55.

5. Cancer Genome Atlas Research N. Comprehensive molecular characterization of gastric adenocarcinoma. Nature 2014,513:202-9. 
6. Weidle UH, Evtimova V, Alberti S, et al. Cell growth stimulation by CRASH, an asparaginase-like protein overexpressed in human tumors and metastatic breast cancers. Anticancer Res 2009,29:95163.

7. Evtimova V, Zeillinger R, Kaul S, et al. Identification of CRASH, a gene deregulated in gynecological tumors. Int J Oncol 2004,24:33-41.

8. Bussolati O, Belletti S, Uggeri J, et al. Characterization of apoptotic phenomena induced by treatment with L-asparaginase in NIH3T3 cells. Exp Cell Res 1995,220:283-91.

9. Salvesen HB, Carter SL, Mannelqvist M, et al. Integrated genomic profiling of endometrial carcinoma associates aggressive tumors with indicators of PI3 kinase activation. Proc Natl Acad Sci U S A 2009,106:4834-9.

10. Wik E, Trovik J, Kusonmano K, et al. Endometrial Carcinoma Recurrence Score (ECARS) validates to identify aggressive disease and associates with markers of epithelial-mesenchymal transition and PI3K alterations. Gynecol Oncol 2014,134:599-606.

11. Edqvist PH, Huvila J, Forsstrom B, et al. Loss of ASRGL1 expression is an independent biomarker for disease-specific survival in endometrioid endometrial carcinoma. Gynecol Oncol 2015,137:529-37.

12. Liu L, Dai Y, Chen J, et al. Maelstrom promotes hepatocellular carcinoma metastasis by inducing epithelial-mesenchymal transition by way of Akt/GSK-3beta/Snail signaling. Hepatology 2014,59:531-43.

13. Altman DG, McShane LM, Sauerbrei W, et al. Reporting Recommendations for Tumor Marker Prognostic Studies (REMARK): explanation and elaboration. PLoS Med 2012,9:e1001216.

14. Pullar CE, Chen J, Isseroff RR. PP2A activation by beta2-adrenergic receptor agonists: novel regulatory mechanism of keratinocyte migration. J Biol Chem 2003,278:22555-62.

15. Fattahi S, Amjadi-Moheb F, Tabaripour R, et al. PI3K/AKT/mTOR signaling in gastric cancer: Epigenetics and beyond. Life Sci 2020,262:118513.

16. Kang BW, Chau I. Molecular target: pan-AKT in gastric cancer. ESMO Open 2020,5:e000728.

17. Koushyar S, Powell AG, Vincan E, et al. Targeting Wnt Signaling for the Treatment of Gastric Cancer. Int J Mol Sci 2020,21.

18. Lin J, Song T, Li C, et al. GSK-3beta in DNA repair, apoptosis, and resistance of chemotherapy, radiotherapy of cancer. Biochim Biophys Acta Mol Cell Res 2020,1867:118659.

19. Baretton G, Kreipe HH, Schirmacher P, et al. HER2 testing in gastric cancer diagnosis: insights on variables influencing HER2-positivity from a large, multicenter, observational study in Germany. Virchows Arch 2019,474:551-560.

20. Biswas P, Chavali VR, Agnello G, et al. A missense mutation in ASRGL1 is involved in causing autosomal recessive retinal degeneration. Hum Mol Genet 2016,25:2483-2497.

21. Li W, Irani S, Crutchfield A, et al. Intramolecular Cleavage of the hASRGL1 Homodimer Occurs in Two Stages. Biochemistry 2016,55:960-9. 
22. Bush LA, Herr JC, Wolkowicz M, et al. A novel asparaginase-like protein is a sperm autoantigen in rats. Mol Reprod Dev 2002,62:233-47.

23. Fonnes T, Berg HF, Bredholt T, et al. Asparaginase-like protein 1 is an independent prognostic marker in primary endometrial cancer, and is frequently lost in metastatic lesions. Gynecol Oncol 2018,148:197-203.

24. De Lange $R$, Burtscher $H$, Jarsch $M$, et al. Identification of metastasis-associated genes by transcriptional profiling of metastatic versus non-metastatic colon cancer cell lines. Anticancer Res 2001,21:2329-39.

25. Evtimova V, Schwirzke M, Tarbe N, et al. Identification of breast cancer metastasis-associated genes by chip technology. Anticancer Res 2001,21:3799-806.

26. Mancinelli R, Carpino G, Petrungaro S, et al. Multifaceted Roles of GSK-3 in Cancer and AutophagyRelated Diseases. Oxid Med Cell Longev 2017,2017:4629495.

\section{Tables}

Table 1 Correlations between ASRGL1 expression level and clinicopathological variables of 100 cases of GC. 


\begin{tabular}{|c|c|c|c|c|}
\hline \multirow[b]{2}{*}{ Clinicopathologic Variables } & \multirow[b]{2}{*}{$\mathrm{n}$} & \multicolumn{3}{|c|}{ ASRGL1 expression } \\
\hline & & Low & High & $P$ Value \\
\hline \multicolumn{5}{|l|}{ Gender } \\
\hline Male & 61 & 24 & 37 & \\
\hline Female & 39 & 17 & 22 & 0.683 \\
\hline \multicolumn{5}{|l|}{ Age(years) } \\
\hline$\leq 60$ & 71 & 31 & 40 & \\
\hline$>60$ & 29 & 10 & 19 & 0.503 \\
\hline \multicolumn{5}{|l|}{ Histological grade } \\
\hline Well and moderate & 34 & 16 & 18 & \\
\hline Poor and other & 66 & 25 & 41 & 0.398 \\
\hline \multicolumn{5}{|l|}{ Drinking history } \\
\hline No & 75 & 32 & 43 & \\
\hline Yes & 25 & 9 & 16 & 0.642 \\
\hline \multicolumn{5}{|l|}{ Family History of malignancy } \\
\hline No & 86 & 34 & 52 & \\
\hline Yes & 14 & 7 & 7 & 0.561 \\
\hline \multicolumn{5}{|l|}{ CEA } \\
\hline$\otimes 5.00 \mathrm{ng} / \mathrm{ml}$ & 85 & 33 & 52 & \\
\hline$\geq 5.00 \mathrm{ng} / \mathrm{ml}$ & 15 & 8 & 7 & 0.394 \\
\hline \multicolumn{5}{|l|}{ Tumor location } \\
\hline fundus and cardia & 13 & 5 & 8 & \\
\hline Body & 42 & 17 & 25 & \\
\hline Antrum & 45 & 19 & 26 & 0.967 \\
\hline \multicolumn{5}{|l|}{ Lauren's classification } \\
\hline Intestinal type & 36 & 15 & 21 & \\
\hline Diffuse type & 64 & 26 & 38 & 0.387 \\
\hline \multicolumn{5}{|l|}{ T stage } \\
\hline $\mathrm{T} 1-\mathrm{T} 2$ & 38 & 21 & 17 & \\
\hline
\end{tabular}




\begin{tabular}{|c|c|c|c|c|}
\hline Т3-Т4 & 62 & 20 & 42 & 0.036 \\
\hline \multicolumn{5}{|c|}{ Lymph node metastasis } \\
\hline Presence & 57 & 19 & 38 & \\
\hline Absence & 43 & 22 & 21 & 0.100 \\
\hline \multicolumn{5}{|l|}{ TNM stage } \\
\hline $\mathbb{Q}-\mathbb{Z}$ & 37 & 10 & 27 & \\
\hline$\nabla-\nabla$ & 63 & 31 & 32 & 0.036 \\
\hline
\end{tabular}

Table 2 The Cox regression analyses of overall survival (OS) and ASRGL1 expression level as well as clinicopathological parameters 


\begin{tabular}{|c|c|c|c|c|c|}
\hline \multirow{2}{*}{ Variables } & \multirow[b]{2}{*}{$\mathrm{n}$} & \multicolumn{2}{|c|}{ Univariable analysis } & \multicolumn{2}{|c|}{ Multivariable analysis } \\
\hline & & $\mathrm{HR}(95 \% \mathrm{Cl})$ & $P$ & $\mathrm{HR}(95 \% \mathrm{Cl})$ & $P$ \\
\hline \multicolumn{6}{|l|}{ Gender } \\
\hline Male & 61 & 1 & & & \\
\hline Female & 39 & $0.68(0.33-1.39)$ & 0.289 & NA & NA \\
\hline \multicolumn{6}{|l|}{ Age(years) } \\
\hline$\leq 60$ & 71 & 1 & & & \\
\hline$>60$ & 29 & $1.32(0.74-2.37)$ & 0.344 & NA & NA \\
\hline \multicolumn{6}{|l|}{ Histological grade } \\
\hline Well and moderate & 34 & 1 & & 1 & \\
\hline Poor and other & 66 & $1.63(0.89-2.98)$ & 0.114 & $1.39(0.72-2.68)$ & 0.330 \\
\hline \multicolumn{6}{|l|}{ Drinking history } \\
\hline No & 75 & 1 & & & \\
\hline Yes & 25 & $1.82 \varangle 0.65-5.26 \rrbracket$ & 0.258 & NA & NA \\
\hline \multicolumn{6}{|l|}{$\begin{array}{l}\text { Family history of } \\
\text { malignancy }\end{array}$} \\
\hline No & 86 & 1 & & & \\
\hline Yes & 14 & $1.13 \otimes 0.35-3.68 \rrbracket$ & 0.839 & NA & NA \\
\hline \multicolumn{6}{|l|}{ CEA } \\
\hline$\otimes 5.00 \mathrm{ng} / \mathrm{ml}$ & 85 & 1 & & & \\
\hline$\geq 5.00 \mathrm{ng} / \mathrm{ml}$ & 15 & $1.45(0.42-4.93)$ & 0.555 & NA & NA \\
\hline \multicolumn{6}{|l|}{ Tumor location } \\
\hline Antrum & 13 & 1 & & 1 & \\
\hline Fundus and Body & 87 & $0.45 \llbracket 0.19-1.07 \rrbracket$ & 0.070 & $0.52 \bowtie 0.13-1.99 \rrbracket$ & 0.339 \\
\hline \multicolumn{6}{|c|}{ Lauren's classification } \\
\hline Intestinal type & 36 & 1 & & & \\
\hline Diffuse type & 64 & $1.12 \varangle 0.42-2.37 \rrbracket$ & 0.965 & NA & NA \\
\hline \multicolumn{6}{|l|}{ T stage } \\
\hline $\mathrm{T} 1-\mathrm{T} 2$ & 38 & 1 & & & \\
\hline
\end{tabular}




\begin{tabular}{|c|c|c|c|c|c|}
\hline T3-Т4 & 62 & $1.21(0.68-2.16)$ & 0.513 & NA & NA \\
\hline \multicolumn{6}{|c|}{ Lymph node metastasis } \\
\hline Presence & 57 & 1 & & 1 & \\
\hline Absence & 43 & $0.46(0.26-0.81)$ & 0.007 & $0.29(0.20-0.63)$ & $<0.001$ \\
\hline \multicolumn{6}{|l|}{ TNM stage } \\
\hline 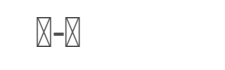 & 37 & 1 & & 1 & \\
\hline$\nabla-\square$ & 63 & $3.22(1.82-5.69)$ & $<0.001$ & $2.45(1.32-4.55)$ & 0.004 \\
\hline \multicolumn{6}{|c|}{ ASRGL1 expression } \\
\hline Low & 41 & 1 & & 1 & \\
\hline High & 59 & $2.13(1.15-3.94)$ & 0.016 & $2.31(1.21-4.39)$ & 0.011 \\
\hline
\end{tabular}

Table 3 The Cox regression analyses of relapse-free survival (RFS) and ASRGL1 expression level as well as clinicopathological parameters 


\begin{tabular}{|c|c|c|c|c|c|}
\hline \multirow{2}{*}{ Variables } & \multirow[b]{2}{*}{$\mathrm{n}$} & \multicolumn{2}{|c|}{ Univariable analysis } & \multicolumn{2}{|c|}{ Multivariable analysis } \\
\hline & & $\mathrm{HR}(95 \% \mathrm{Cl})$ & $P$ & $\mathrm{HR}(95 \% \mathrm{Cl})$ & $P$ \\
\hline \multicolumn{6}{|l|}{ Gender } \\
\hline Male & 61 & 1 & & & \\
\hline Female & 39 & $0.72(0.35-1.49)$ & 0.380 & NA & NA \\
\hline \multicolumn{6}{|l|}{ Age(years) } \\
\hline$\leq 60$ & 71 & 1 & & & \\
\hline$>60$ & 29 & $0.79(0.42-1.49)$ & 0.460 & NA & NA \\
\hline \multicolumn{6}{|l|}{ Histological grade } \\
\hline Well and moderate & 34 & 1 & & 1 & \\
\hline Poor and other & 66 & $1.52(0.84-2.76)$ & 0.114 & $1.48(0.78-2.81)$ & 0.226 \\
\hline \multicolumn{6}{|l|}{ Drinking history } \\
\hline No & 75 & 1 & & & \\
\hline Yes & 25 & $0.98 \bowtie 0.94-1.02 \rrbracket$ & 0.322 & NA & NA \\
\hline \multicolumn{6}{|c|}{ Family history of malignancy } \\
\hline No & 86 & 1 & & & \\
\hline Yes & 14 & $1.27 \rrbracket 0.32-2.83 \rrbracket$ & 0.653 & NA & NA \\
\hline \multicolumn{6}{|l|}{ CEA } \\
\hline$\otimes 5.00 \mathrm{ng} / \mathrm{ml}$ & 85 & 1 & & & \\
\hline$\geq 5.00 \mathrm{ng} / \mathrm{ml}$ & 15 & $1.31(0.34-2.13)$ & 0.423 & NA & NA \\
\hline \multicolumn{6}{|l|}{ Tumor location } \\
\hline Antrum & 13 & 1 & & 1 & \\
\hline Fundus and Body & 87 & $0.45 \rrbracket 0.19-1.07 \rrbracket$ & 0.070 & $0.52 \varangle 0.13-1.99 \rrbracket$ & 0.339 \\
\hline \multicolumn{6}{|c|}{ Lauren's classification } \\
\hline Intestinal type & 36 & 1 & & & \\
\hline Diffuse type & 64 & $1.39(0.59-3.28)$ & 0.462 & NA & NA \\
\hline \multicolumn{6}{|l|}{ T stage } \\
\hline T1-T2 & 38 & 1 & & & \\
\hline T3-T4 & 62 & $1.21(0.68-2.16)$ & 0.513 & NA & NA \\
\hline
\end{tabular}


Lymph node metastasis

\begin{tabular}{|c|c|c|c|c|c|}
\hline Presence & 57 & 1 & & 1 & \\
\hline Absence & 43 & $0.47(0.26-0.85)$ & 0.013 & $0.38(0.20-0.72)$ & 0.003 \\
\hline \multicolumn{6}{|l|}{ TNM stage } \\
\hline 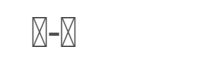 & 37 & 1 & & 1 & \\
\hline 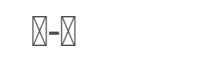 & 63 & $2.50(1.37-4.57)$ & 0.003 & $1.95(1.03-3.71)$ & 0.041 \\
\hline \multicolumn{6}{|c|}{ ASRGL1 expression } \\
\hline Low & 41 & 1 & & 1 & \\
\hline High & 59 & 1.98 (1.09-3.58) & 0.024 & $1.97(1.06-3.65)$ & 0.031 \\
\hline
\end{tabular}

Figures 

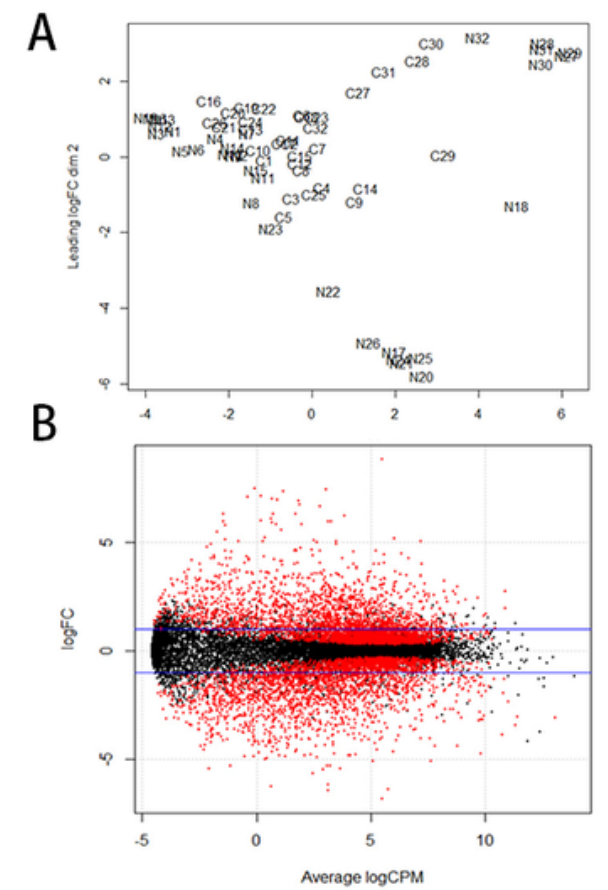

C

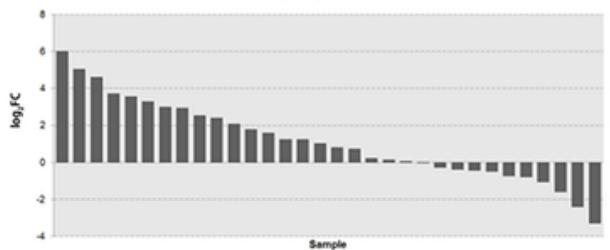

$E$

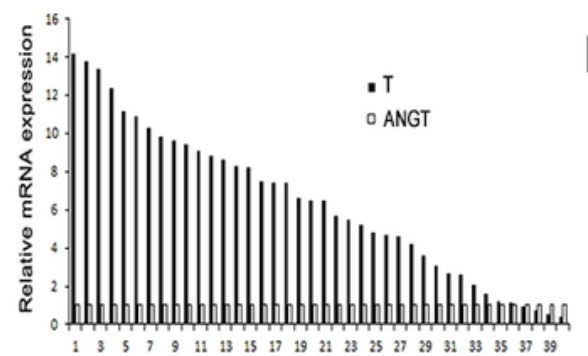

G

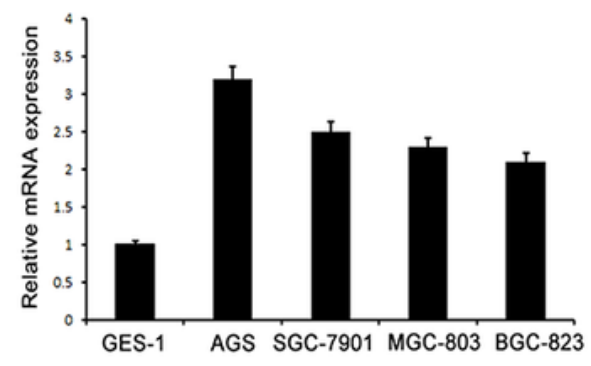

D

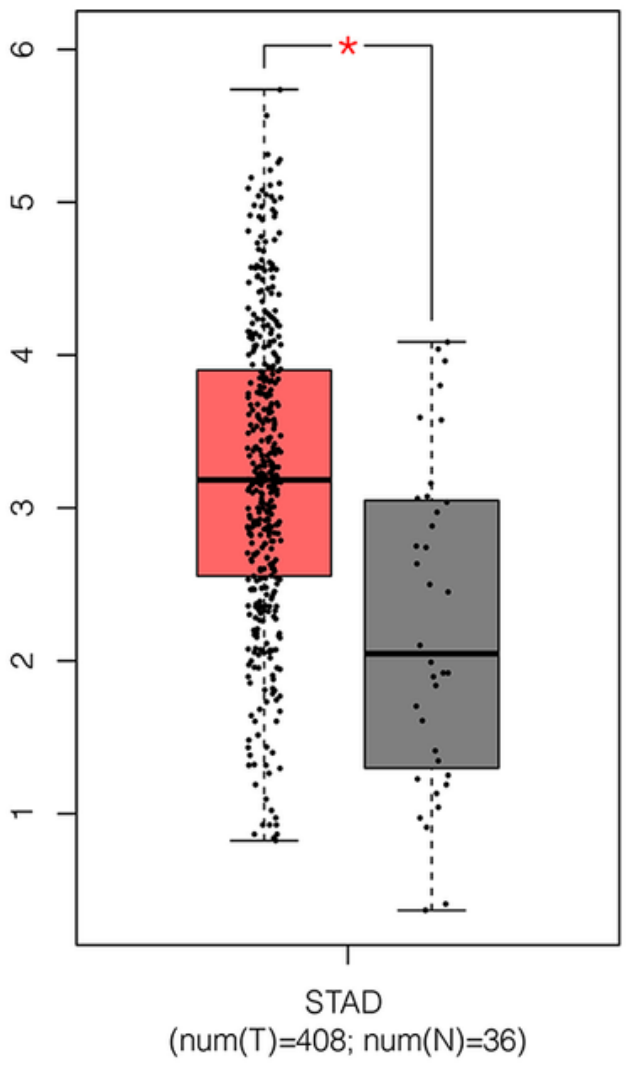

F

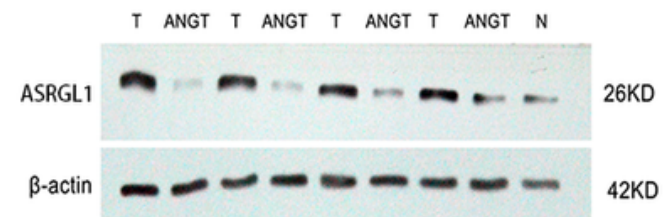

$\mathrm{H}$

ASRGL1

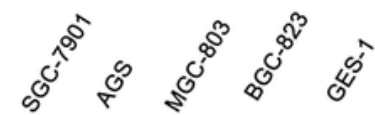

$\beta$-actin

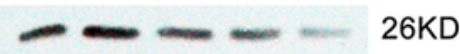

26KD

$42 \mathrm{KD}$

\section{Figure 1}

ASRGL1 expression is up-regulated in GC tissues. (A) The biological coefficient of variation (BCV) for quality control was used to avoid the error caused by improper sample grouping. (B) The general linear model was used to estimate the differences in genes among different groups. (C) The expression level of ASRGL1 in gastric cancer was 2.136 times higher than that in adjacent gastric tissue samples in TCGA database. (D) The expression level of ASRGL1 in gastric cancer was significantly higher than that in 
normal gastric tissue in TCGA database. (E\&G) Real-time PCR showed the mRNA expression of ASRGL1 is up-regulated in human GC tissues and cell lines. (F\&H) Western blotting showed the protein expression of ASRGL1 is up-regulated in human GC cell lines and tumor tissues. Abbreviations: T, GC tissue. ANGT, adjacent nontumor gastric tissues. ${ }^{*} \mathrm{P}<0.05$ based on the Student $t$ test.

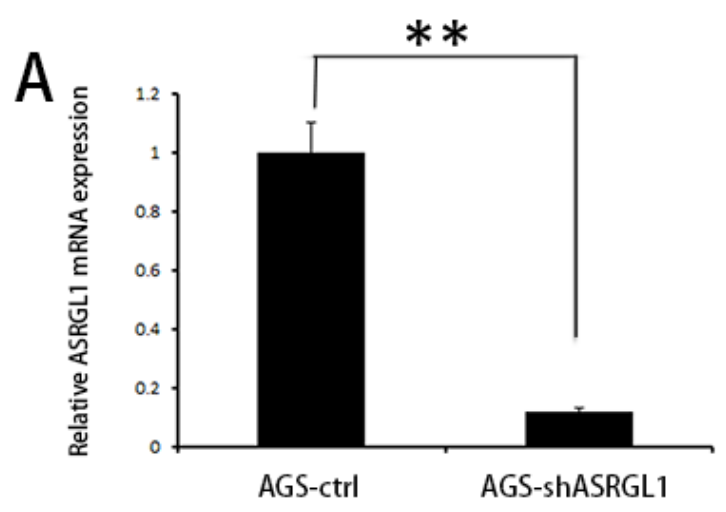

C

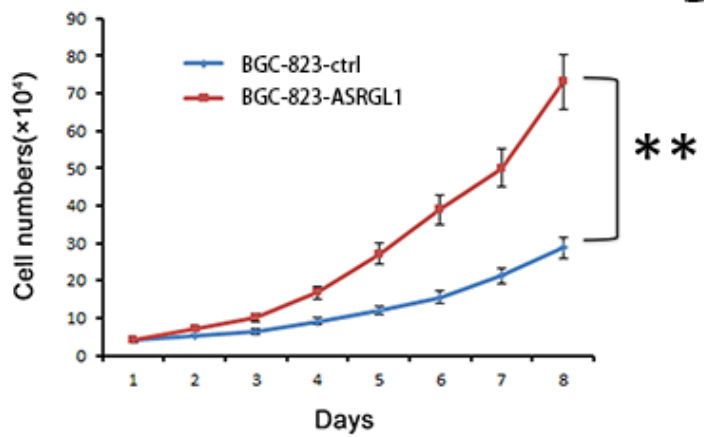

E

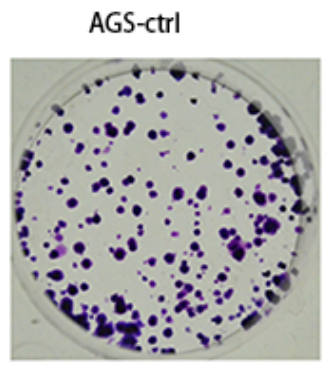

F

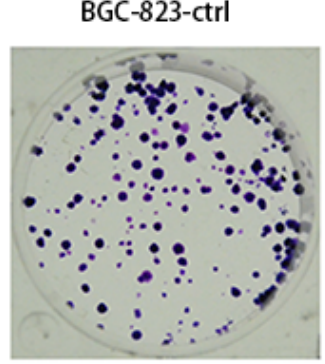

AGS-shASRGL1

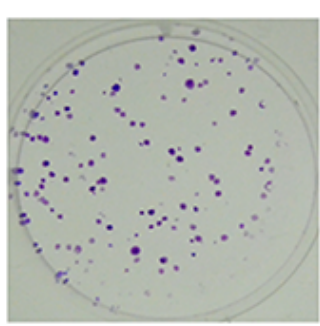

BGC-823-ASRGL1

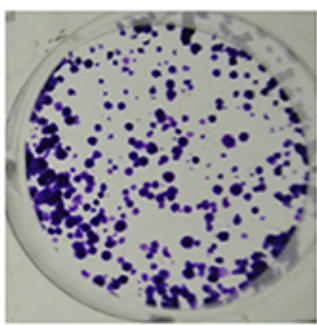

**

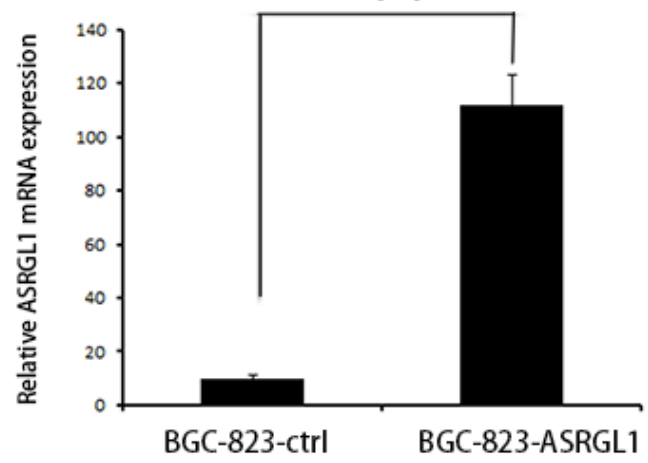

D
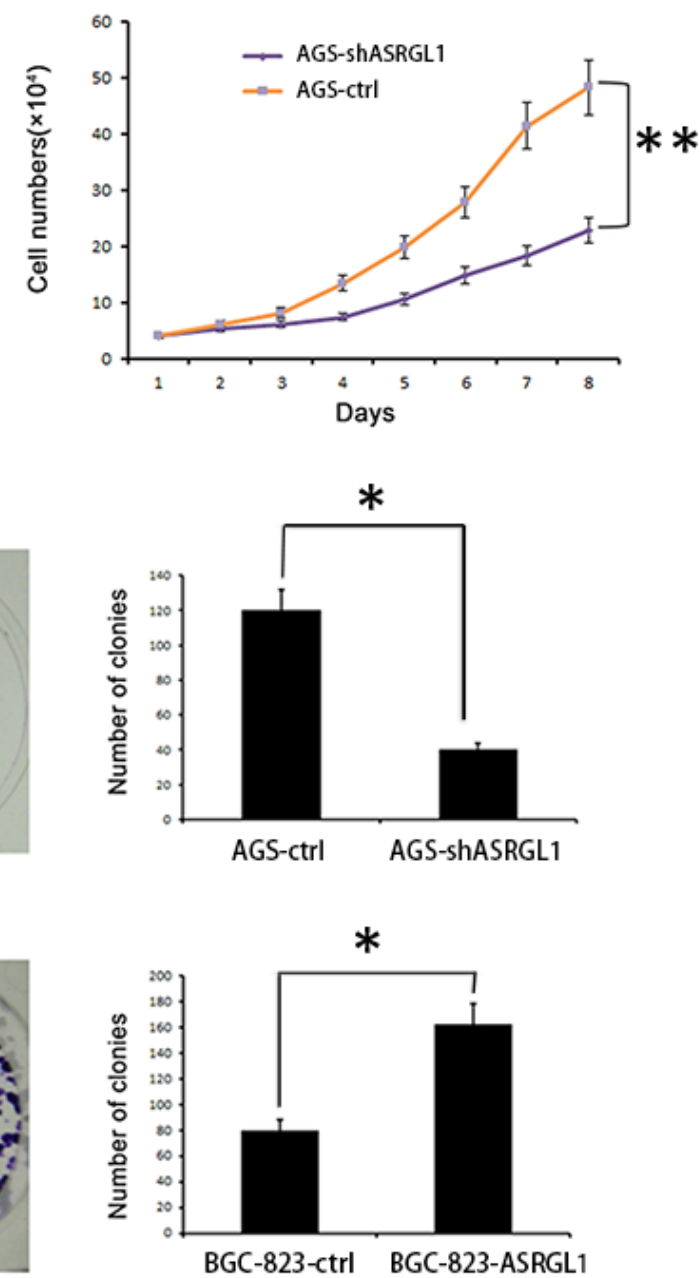

Figure 2 
ASRGL1 promotes proliferation of GC in vitro. (A\&B) Expression level of ASRGL1 was identified by realtime PCR in AGS-ctrl, AGS-shASRGL1, BGC-823-ctrl and BGC-823-ASRGL1 cells. (C\&D) Proliferation of AGs-shASRGL1, BGC-823-ASRGL1 cells and control cells was examined by cell proliferation curve assay. (E\&F) Proliferation of AGs-shASRGL1, BGC-823-ASRGL1 cells and control cells was examined by colony formation assay. ${ }^{*} P<0.05,{ }^{*} \mathrm{P}<0.01$ based on the Student $t$ test.

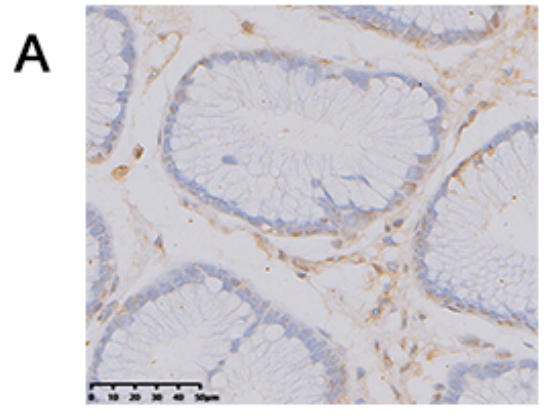

ANGTs

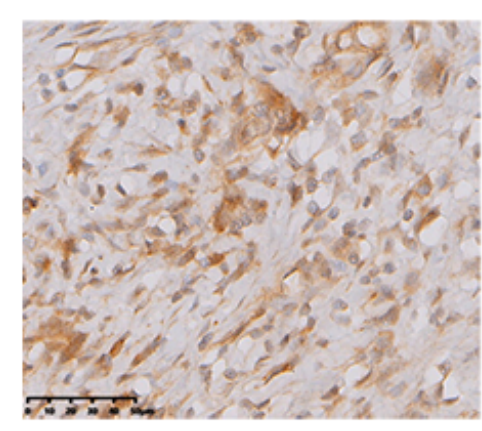

Nonmetastasis Tumor

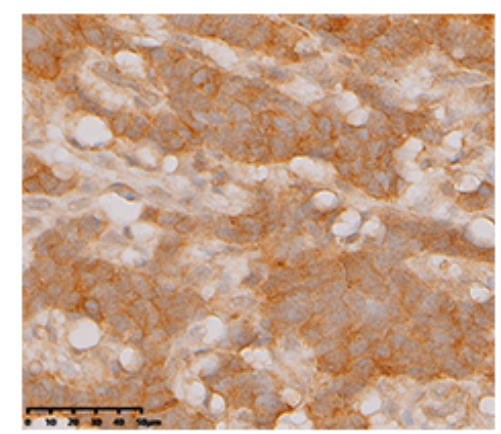

Metastasis Tumor

B

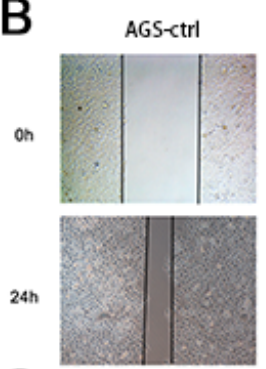

C

on

BGC-823-ctrl

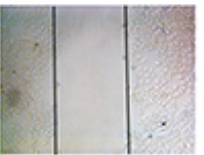

$24 h$

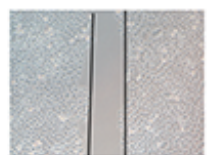

AGS-shASRGL1

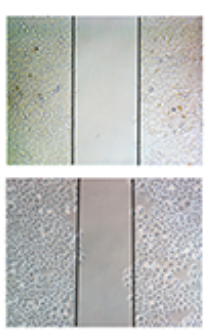

BGC-823-ASRGL1
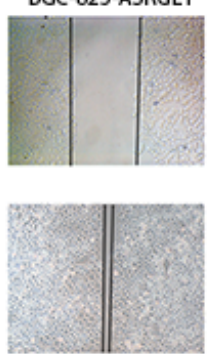
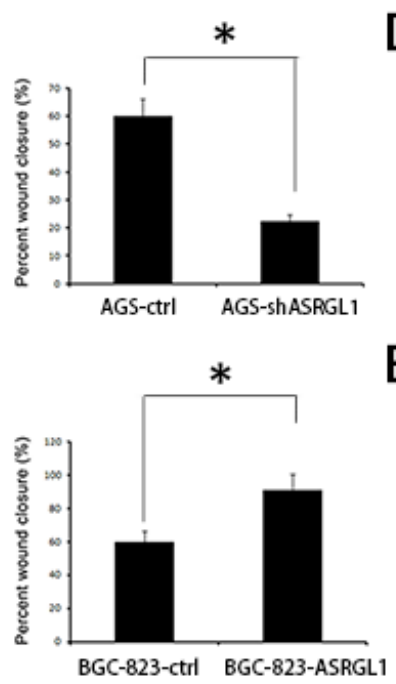

D
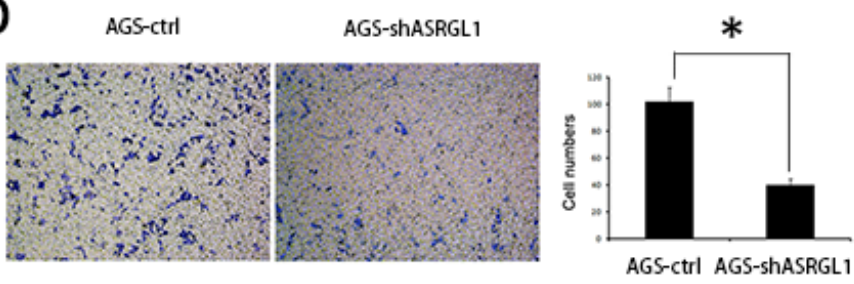

E
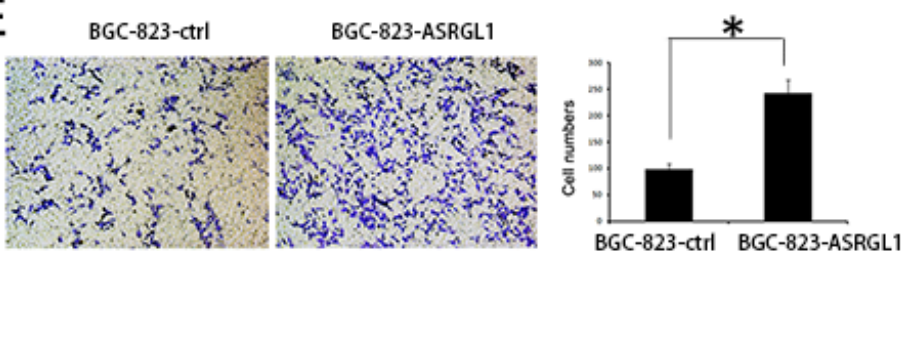

Figure 3

ASRGL1 promotes migration and invasion of GC. (A) Representative IHC images of ASRGL1 expression in ANGTs, nonmetastasis tumor tissues and metastasis tumor tissues. (B\&C) Wound-healing assay was subjected to detect the migration capacity of ASRGL1-interfered cells. (D\&E) Transwell invasion assay was subjected to detect the invasion capacity of ASRGL1-interfered cells. ${ }^{*} \mathrm{P}<0.05$ based on the Student $t$ test. 
A

AGS-ctrl

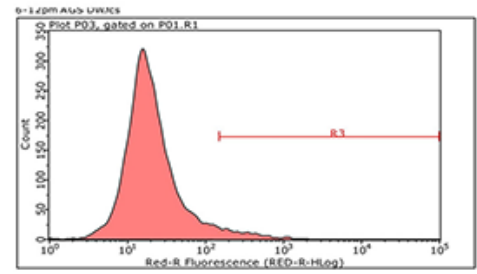

ANNEXIN-V

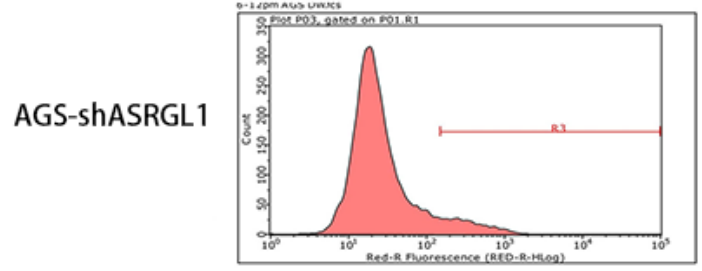

ANNEXIN-V

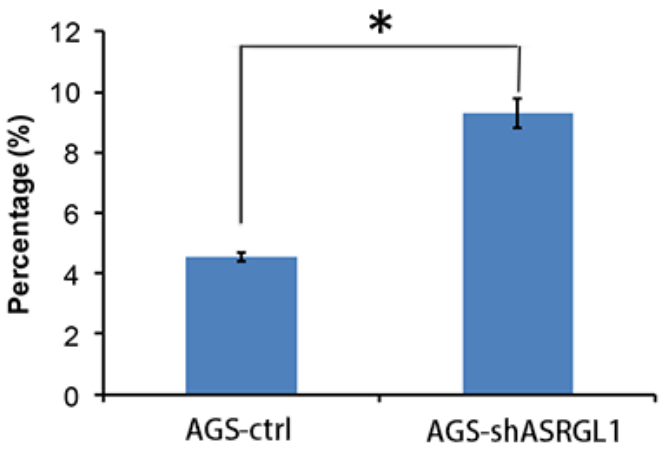

C

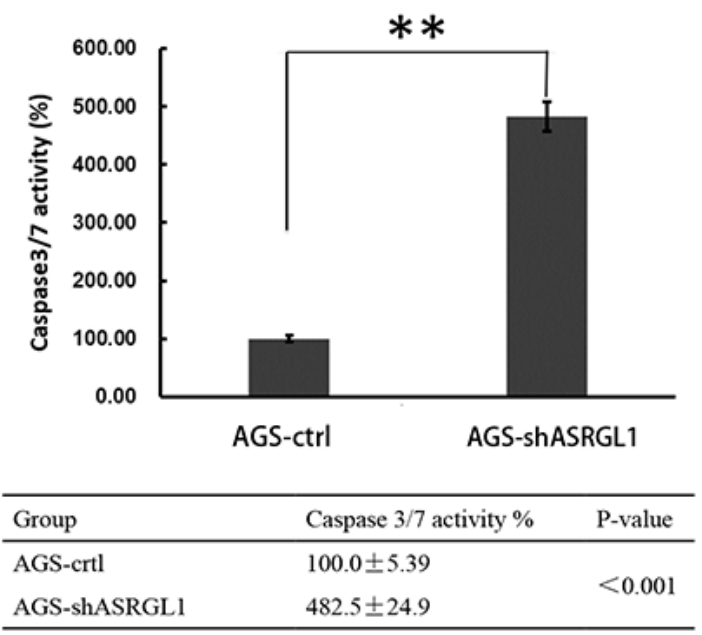

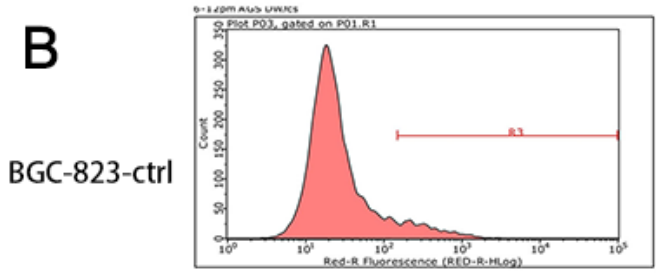

ANNEXIN-V

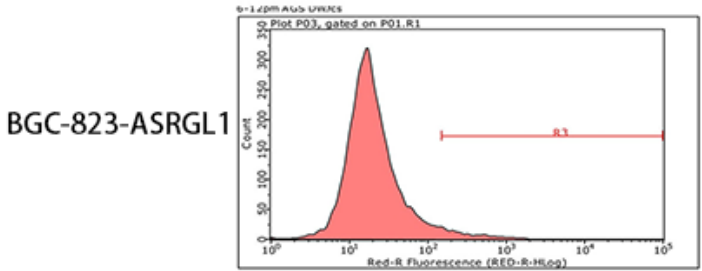

ANNEXIN-V

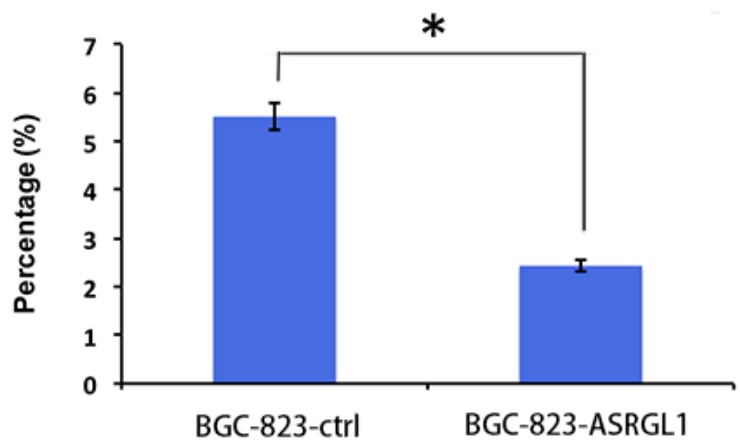

D

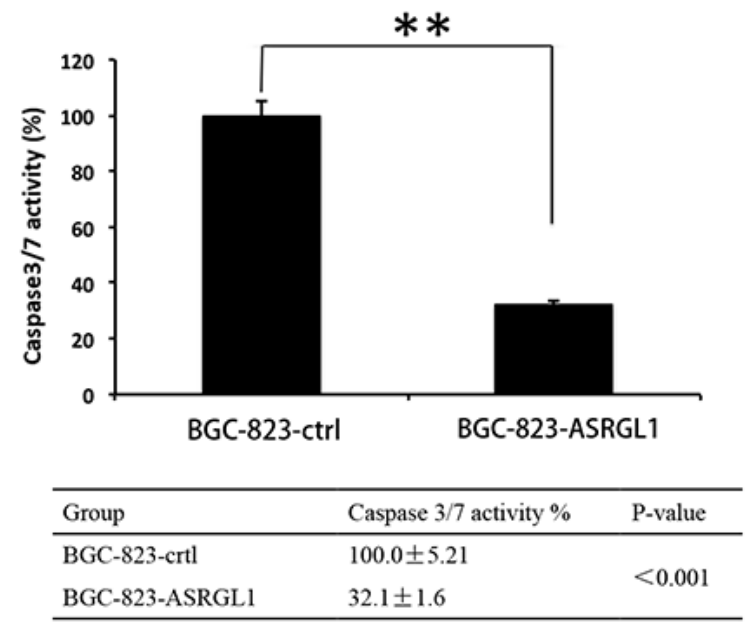

\section{Figure 4}

ASRGL1 inhibits GC cell apoptosis. (A\&B) Annexin V-APC single staining flow cytometry to detect the apoptosis percentage of ASRGL1-interfered cells . (C\&D) Caspase 3/7 detection was used to detect the apoptosis percentage of ASRGL1-interfered cells. ${ }^{\star} \mathrm{P}<0.05,{ }^{\star} * \mathrm{P}<0.01$ based on the Student $t$ test. 

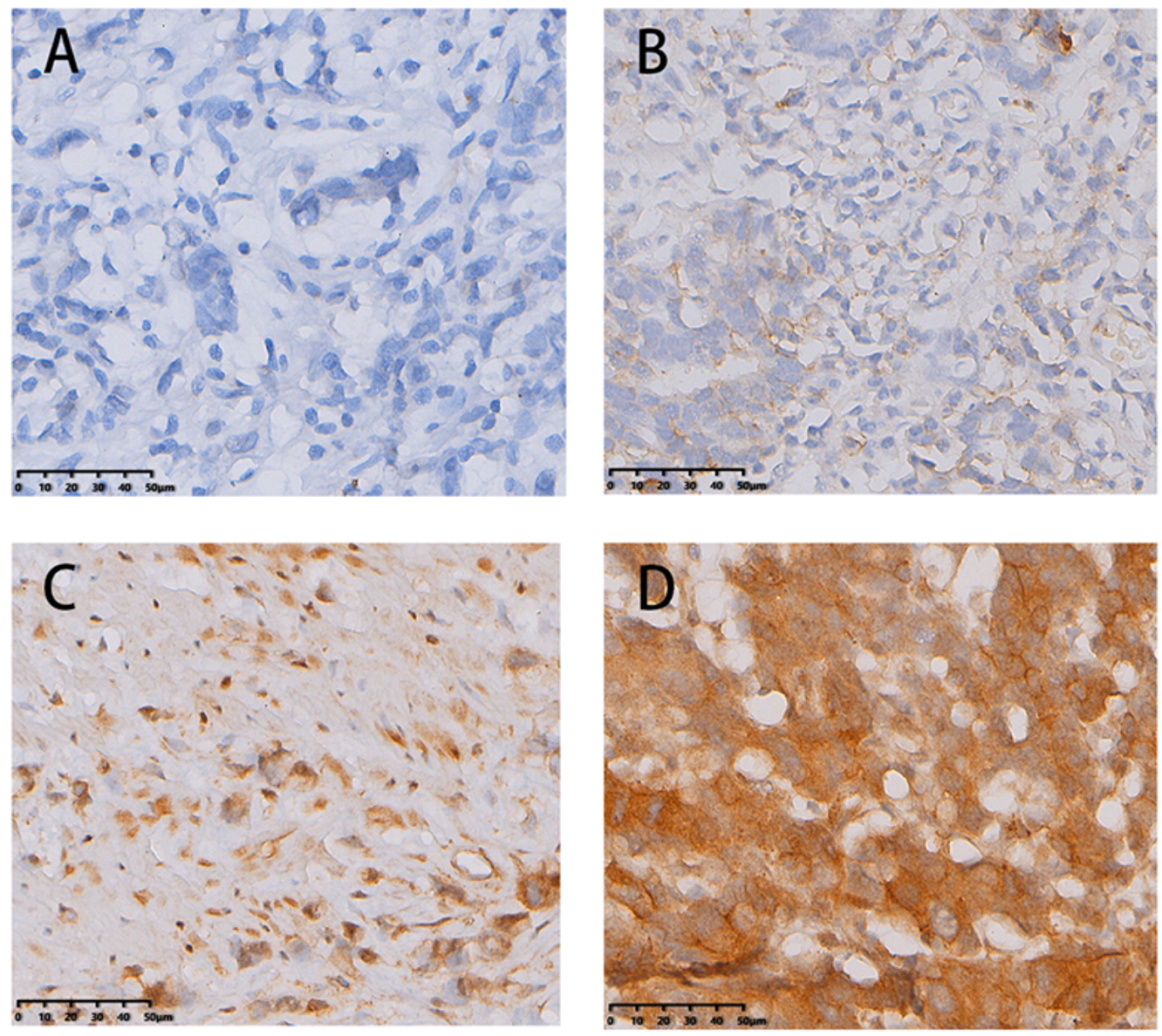

\section{$\mathrm{E}$}
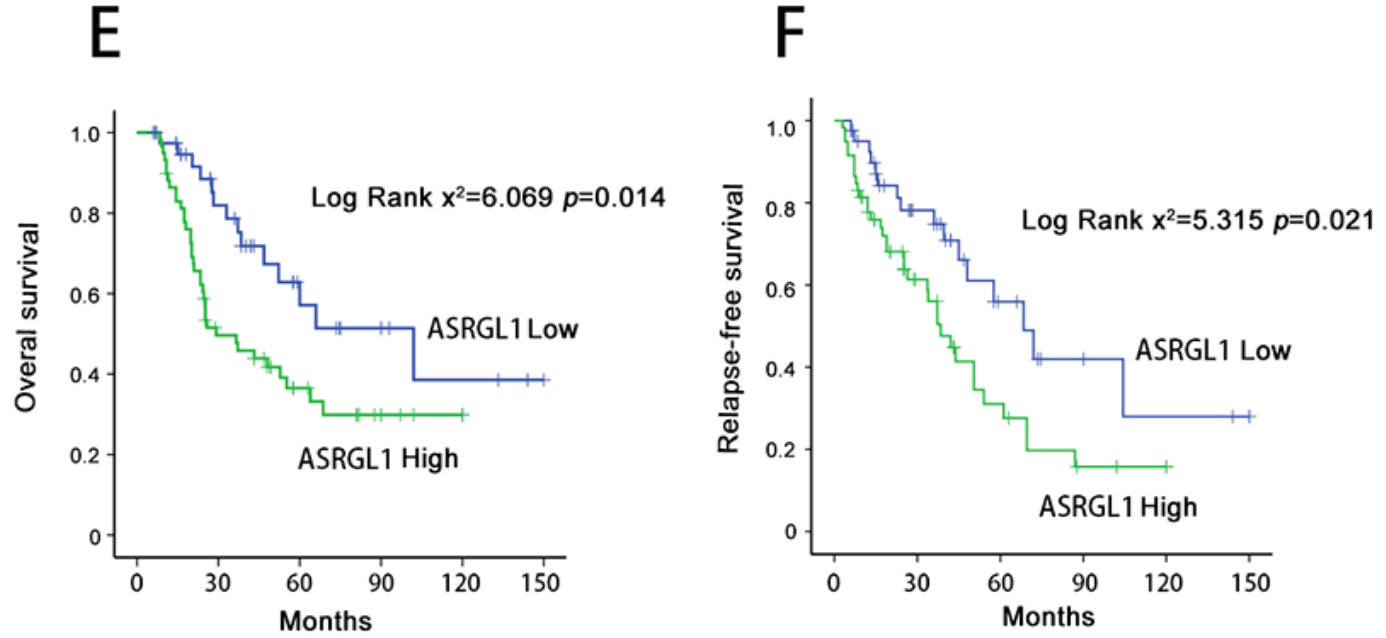

\section{Figure 5}

High ASRGL1 expression indicates poor prognosis. (A-D) Representative IHC images of ASRGL1 expression in GC tissues. (E\&F) OS and RFS of GC patients with high or low ASRGL1 expression. Survival curve was calculated with the log-rank test. 
A

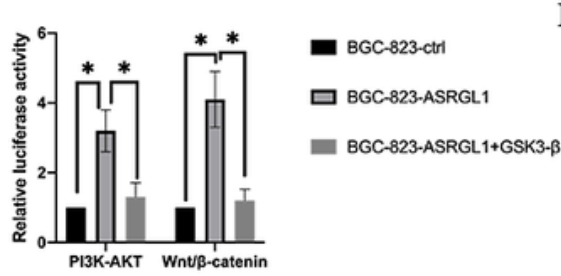

B

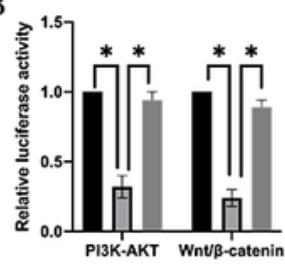

- AGS-ctrl

AGS-ShASRGL1

AGS-shASRGL1+shGSK3- $\beta$
C
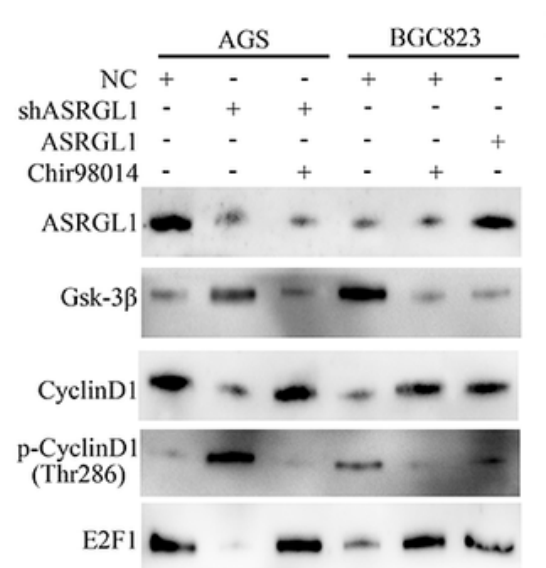

$\mathrm{AKT}--\cdots$

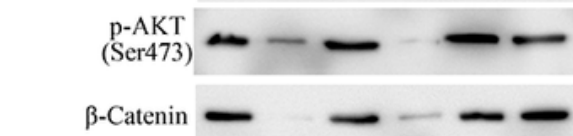

$\mathrm{p}-\beta$-Catenin (Ser33/37/Thr41)

GAPDH

D
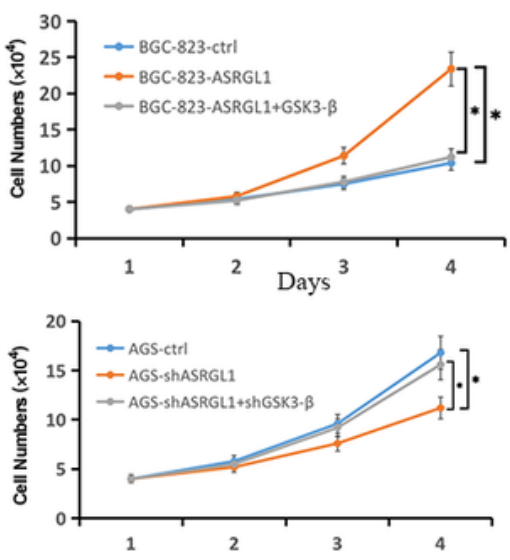

Days
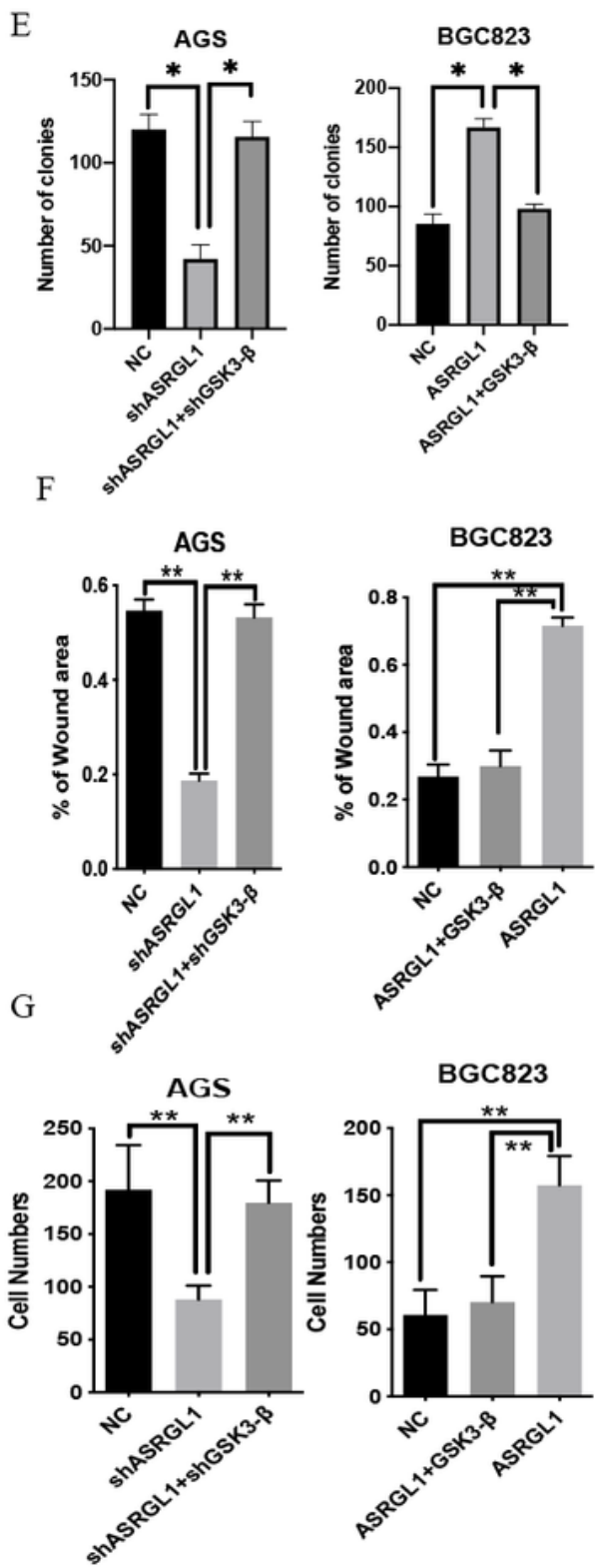

\section{Figure 6}

ASRGL1 activates PI3K-AKT and Wnt/ $\beta$-catenin signaling through interacts with GSK3- $\beta$. (A) Overexpression of GSK3- $\beta$ in BGC-823-ASRGL1 cells eliminated the activated effect of ASRGL1 on PI3KAKT and Wnt/ $\beta$-catenin signaling. (B) Knockdown of GSK3- $\beta$ in AGS-shASRGL1 cells restored the PI3KAKT and Wnt/ $\beta$-catenin signaling activity. (C) ASRGL1 regulates the expression of GSK3- $\beta$ and its downstream proteins in ASRGL1-interfered GC cells. (D\&E) Cell proliferation curve (D) and colony 
formation assays (E) were used to examine the effects of GSK3- $\beta$ in ASRGL1-interfered cells on gastric cancer cell proliferation. (F\&G) Wound-healing assay (F) and transwell invasion assay (G) were subjected to detect the effects of GSK3- $\beta$ in ASRGL1-interfered cells on gastric cancer cell migration and invasion. ${ }^{*} \mathrm{P}<0.05,{ }^{*} \mathrm{P}<0.01$ based on the Student $\mathrm{t}$ test.

\section{Supplementary Files}

This is a list of supplementary files associated with this preprint. Click to download.

- SupplementaryTables.docx

- Supplementaryfigurelegends.docx

- SuppleFig1.tif

- supplementaryfig2.tif 